HERMAEA

\title{
GERMANISTISCHE FORSCHUNGEN
}

NEUE FOLGE

HERAUSGEGEBEN VON

CHRISTINE LUBKOLL UND STEPHAN MÜLLER

BAND 129 

JAKUB ŠIMEK

\section{Die `Acht Seligkeiten des Prager Predigers Heinrich von St. Gallen}

De Gruyter 
Gedruckt mit freundlicher Unterstützung des Förderungs- und Beihilfefonds Wissenschaft der VG Wort und der Geschwister Boehringer Stiftung Ingelheim für Geisteswissenschaften in Ingelheim am Rhein.

ISBN 978-3-11-027967-2

e-ISBN 978-3-11-028949-7

ISSN 0440-7164

\section{Library of Congress Cataloging-in-Publication Data}

A CIP catalogue record for this book is available from the Library of Congress.

Bibliografische Information der Deutschen Nationalbibliothek

Die Deutsche Nationalbibliothek verzeichnet diese Publikation in der Deutschen Nationalbibliografie; detaillierte bibliografische Daten sind im Internet über http://dnb.d-nb.de abrufbar.

(C) 2013 Walter de Gruyter GmbH, Berlin/Boston

Druck: Hubert \& Co. GmbH \& Co. KG, Göttingen

$\infty$ Gedruckt auf säurefreiem Papier

Printed in Germany

www.degruyter.com 